\title{
城市河流改造工程对河流生态系统野生 维管植物的影响
}

\author{
王应刚 ${ }^{12}$ 张秋华 ${ }^{2}$ 张 峰 ${ }^{12 *}$ 朱宇恩 ${ }^{2}$ \\ （1 山西大学黄土高原研究所,太原 030006)（2 山西大学环境与资源学院,太原 030006)
}

\begin{abstract}
摘 要 随着城市化的发展, 许多城市对流经市区的河流进行了大规模工程改造, 在获得了多种效益的同时, 也引 起了诸如生物多样性破坏和物种组成改变等一系列生态问题, 因此对城市河流改造工程的生态影响进行研究非常 重要 将有助于在未来城市河流改造中更有效地保护河流生态系统。该文以汾河太原段的河道改造工程为研究对 象, 用 Shannon-Weiner 多样性指数、Sørensen 群落相似性指数和单因素方差分析方法, 研究了河流改造工程对河流生 态系统中的野生维管植物物种多样性、频度和群落物种组成相似性的影响。结果表明:太原汾河段改造后比改造 前的野生维管植物物种数和 Shannon-Weiner 多样性指数显著降低; 低频度的物种数明显增加而高频度的物种数明 显减少, 河流改造前后的群落相似性明显降低。由此可见, 城市河流改造工程对河流生态系统中的野生维管植物 物种多样性、频度和群落相似性有明显影响。
\end{abstract}

关键词 汾河 城市化 河流改造工程 群落相似性 城市河流

\section{IMPACTS OF URBAN RIVER RECONSTRUCTION ON NATIVE VASCULAR PLANTS IN A CHINESE RIVER ECOSYSTEM}

\author{
WANG Ying-Gang ${ }^{1}{ }^{2}$, ZHANG Qiu-Hua ${ }^{2}$, ZHANG Feng $^{1}{ }^{2 *}$, and ZHU Yu-En ${ }^{2}$ \\ ${ }^{1}$ Institue of Loess Plateau , Shanxi University , Taiyuan 030006 , China , and ${ }^{2}$ School of Environment and Resources , Shanxi University , Taiyuan \\ 030006 , China
}

\begin{abstract}
Aims Some urban river segments are reconstructed, resulting in benefits as well as ecological problems including reduced species diversity and altered species composition. Therefore, better understanding of the ecological impacts of urban river reconstruction projects is important for effectively protecting river ecosystems in future projects.

Methods We studied a $4.2 \mathrm{~km}$ river reconstruction project of Fenhe River in Taiyuan , using 30 random sample plots before (1997) and after (2003) reconstruction. We examined impacts of the project on species diversity , frequency and community similarity of native vascular plants using the Shannon-Weiner index , Sørensen index and one-factor analysis of variance.

Important findings Species richness and Shannon-Weiner index values decreased after reconstruction. In addition , the number of low frequency species increased , the number of high frequency species decreased and the similarity of species composition before and after reconstruction was low. Therefore, the impacts of this urban river reconstruction project on the species diversity , frequency and community similarity of native vascular plants were substantial.
\end{abstract}

Key words Fenhe river, urbanization, river reconstruction project, community similarity, urban river

在全球城市化发展过程中，国内外许多城市对 流经市区的河流进行了大规模工程改造 (吴保生等， 2004）,在获得了多种效益的同时,也引起了许多生 态环境问题 (杜淑如等，1997;Freeman \& Ray ,2001； Konishi ,2000)。进入 20 世纪 80 年代以来，我国的许
多城市对流经城市地区的河流也进行了工程改造 (宋庆辉和杨志峰, 2002)。近年来, 国内外学者对河 流改造工程所产生的影响做了许多研究(董哲仁, 2004 ; 崔伟中,2003; Fabos,2004; 张明和曹梅英, 2002 淣水玉和王祥荣, 1999）,但关于城市河流改造 
工程对野生维管植物影响的研究很少。本文以汾河 太原段 (图 1)的河流改造工程为对象，研究了城市 河流改造工程对野生维管植物的影响，揭示了城市 河流改造工程对河流生态系统中的野生维管植物的 影响规律, 为今后在进行城市河流改造时保护河流 生态系统的野生维管植物提供了依据。

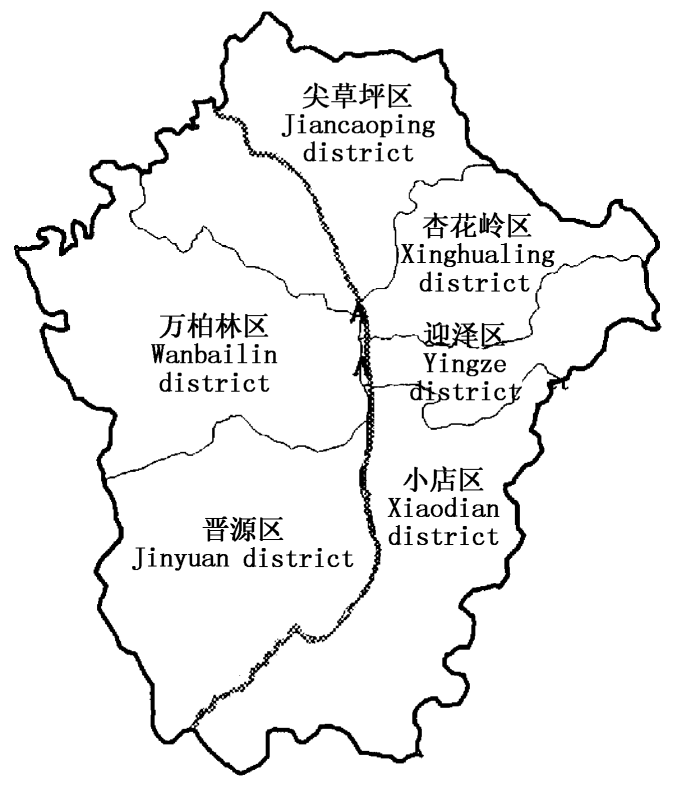

图 1 汾河太原段示意图

Fig. 1 Sketch map of Fenhe River segment in Taiyuan

\section{1 研究地点概况}

\section{1 自然概况}

汾河是山西省的最大河流, 纵贯全省的中部, 发 源于管涔山林区, 由北向南流经太原、临汾两大盆 地, 于河津县西南汇入黄河, 从河源到河口相对高差 为 $2336 \mathrm{~m}$, 全长 $685 \mathrm{~km}$, 流域面积 $3.95 \times 10^{4} \mathrm{~km}^{2}$,多 年平均径流量为 $25.1 \times 10^{8} \mathrm{~m}^{3}$ 。在汾河太原河段， 除了夏季暴雨后短时间内流量较大外，其它季节的 流量均在 $6 \mathrm{~m}^{3} \mathrm{~s}^{-1}$ 以下，所以河床段面的 $83 \%$ 在全 年中的绝大部分时间内处于干涸状态, 因而在河床 上生长着大量植物, 形成了以芦苇 (Phragmites australis) 和香蒲 (Typha angustifolia) 为优势种的沼生植 物群落 (Helophyte community)。汾河纵贯太原市区, 将整个城区分为东西两部分, 河床宽 $360 \mathrm{~m}$,包括河 岸滩在内宽度达 $500 \mathrm{~m}$ 。随着工农业生产的发展和 城市人口的增多，使汾河承受的压力越来越大，进入 20 世纪 80 年代以来, 汾河太原段的污染开始快速 加重, 主要表现为水质下降、水量减少和水生生物减 少。到了 20 世纪 80 年代后期, 在汾河流经太原市
区的河段中，鱼虾已经基本绝迹(杜淑如等, 1997 韩 静和郑凡,2003)。

\section{2 工程概况}

汾河流经太原市城区的长度为 $9.2 \mathrm{~km}$, 汾河太 原城区段的改造治理工程始于 1998 年 10 月动工, 历时两年多时间，对南内环桥到胜利桥之间的 4.2 $\mathrm{km}$ 长的河道进行了人工改造。在改造过程中，采用 了洪水、清水和污水分流的设计方案。城区排放的 污水沿河流两侧暗渠 $(4 \mathrm{~m}$ (宽) $\times 3.5 \mathrm{~m}$ (高) ) 排到下 游; 雨后形成的洪水沿洪水渠 $(80 \mathrm{~m}$ (宽) $\times 4 \mathrm{~m}$ (高) ) 排到下游; 清水渠 $(220 \mathrm{~m}$ (宽) $\times 4 \mathrm{~m}$ (高) ) 用橡皮坝 分段拦截形成长期蓄水的”河湖”。在河道两侧分别 兴建了 $100 \mathrm{~m}$ 宽的人工绿化带。用钢筋混凝土等永 久性建筑材料, 在河流两岸构筑了垂直水泥堤岸, 在 洪水渠和清水渠之间构筑了水泥 中隔墙”, 并用水 泥和石料对河床进行了人工硬化处理。

\section{2 研究方法}

\section{1 样地设置}

按照植被研究中的样地布设原理(李博,1993; 吴中华等，2002）, 针对河流的特点，结合汾河太原段 的实际情况，在汾河改造前的 1997 年 7 月，在即将 动工的 $4.2 \mathrm{~km}$ 长的原河段上，沿纵向划分为 2100 个 $2 \mathrm{~m}$ 宽的横跨河流两岸的断面, 用随机抽样法(杜 荣寒, 1985)抽取 30 个河流断面作为改造前的调查 样方 组成样本 A。然后, 在河流改造工程竣工后的 第三年即 2003 年的 7 月，在已经改造过的 $4.2 \mathrm{~km}$ 长 的河段上，再沿纵向划分为 2100 个 $2 \mathrm{~m}$ 宽的横跨河 流两岸的断面，再次用随机抽样方法重新抽取另外 30 个河流断面作为改造后的调查样方 组成样本 B。 每个调查断面的规格为 $2 \mathrm{~m} \times 500 \mathrm{~m}$, 每个调查断面 都横跨河床和两侧的局部岸滩，这是根据汾河生态 系统的特殊性而采取的非常规样方布设方法,与在 植被数量生态研究中所采用的常规样方布设方法不 同。

\section{2 样地调查}

对河流改造前河段的野生维管植物的调查结果 表明, 在 30 个样方中, 共记录了碱茅 ( Puccinellia distans)、马唐 (Digitaria sanguialis)、画眉草 (Eragrotis pilosa)、反枝苋 (Amaranthus retroflexus)、田旋花 (Convolvulus arvensis)、大蓟 (Cirsium seetosum)、 $\square$ 草 ( Humulus scandens)、红苶( Polygonum orientale)、香蒲和芦 苇等共 88 个野生维管植物种, 隶属于 65 属, 27 科。 种数占总种数 $5 \%$ 以上的科有 4 个, 其中包含菊科、 
禾本科、藜科和豆科。

对河流改造后河段的野生维管植物的调查结果 表明, 在重新抽取的 30 个样方中, 共记录了 $\square$ 草、红 蓼、马齿苋 ( Portulaca oleracea)、宽叶香蒲 ( Typha latifolia)、香蒲、田旋花、水莎草 (Juncellus serotinus)、狗 尾草( Setaria viridis)、芦苇和野大豆 (Glycine soja) 等 共 56 个野生维管植物种, 隶属于 41 属, 23 科。种数 占总物种数 $5 \%$ 以上的科有 5 个, 它们是菊科、禾本 科、香蒲科、藜科和豆科。

\section{3 数据处理}

鉴于汾河生态系统的特殊性, 本研究没有采用 常规方法设置样方, 而是采用了横跨河流的面积比 较大 $\left(1000 \mathrm{~m}^{2}\right)$ 的样方, 在如此大的样方中, 要对各 种草本植物的个体数量进行精确计数是十分困难 的。因此, 本研究中只测定各个物种的分盖度和各 个物种的平均高度, 并用各个物种的总优势比 (Sum of dominance, SDR)代替 Shannon-Weiner 多样性指数 公式中的 $P_{i}$ 值。Shannon-Weiner 多样性指数的计算 公式为：

$$
H=-\sum_{i=1}^{s} P_{i} \ln P_{i}
$$

式中 :s 为样方中的总物种数, $P_{i}$ 为第 $i$ 个物种的 总优势比, $H$ 为 Shannon-Weiner 多样性指数。样方 中的各个物种的总优势比定义为 $S D R=($ 相对盖度 + 相对高度) $/ 2$ 。

用频度公式分别计算河流改造前和河流改造后 的各物种的频度，以确定河流改造工程对各物种个 体分布状况的影响，计算公式为：

$$
F=y / z
$$

式中 : $F$ 为某个物种的频度, $y$ 为某个物种出现的样 方数, $z$ 为调查样方的总数。

用 Sørensen 指数公式来计算河流改造前和改造 后的群落相似性指数, 计算公式为：

$$
S=2 c /(a+b)
$$

式中 : $c$ 为 2 个对比群落中的共有物种数, $a$ 和 $b$ 分 别为该 2 个群落中各含有的物种数, $S$ 为 Sørensen 指数。

用 SPSS 软件(马国庆,2003) 对调查数据作单因 素方差分析，以确定河流改造前后的物种数量和 Shannon-Weiner 指数是否存在差异及其差异的显著 性程度。

\section{3 结果与分析}

3.1 河流改造工程对野生维管植物物种多样性的
影响

为了分析河流改造前和改造后的野生维管植物 物种数的差异和多样性指数的差异, 用 SPSS 工具 对野生维管植物物种数和多样性指数 (表 1) 分别作 单因素方差分析, 进行差异显著性检验。本研究把 河流是否进行过工程改造看作一个因素的两个处理 水平, 运算结果 (表 2)。从表 2 中的数据看出, 当分 子自由度为 1 , 分母自由度为 58 时, $F_{1,58,0.01}=$ 7.120 河流改造前后物种数之间的 $F=51.076, F>$ $F_{158,0.01}$ 表明两个样本之间的物种数差异极显著; 河流改造前后的 Shannon-Weiner 多样性指数之间的 $F=40.876, F>F_{158,0.01}$ 表明两个样本之间的多样 性指数的差异也极显著。

\section{2 河流改造工程对野生维管植物频度的影响}

用频度计算公式对河流改造前和改造后的野生 维管植物物种的频度分别进行计算, 并绘制成频度 图 (图 2)。在图 2 中，凡频度在 1\% 20\%的植物种 归入 A 级, $21 \% \sim 40 \%$ 的植物种归入 B 级, $41 \% \sim$ $60 \%$ 的植物种归入 C 级, 61\% 80\% 的植物种归入 $\mathrm{D}$ 级, $81 \% \sim 100 \%$ 的植物种归入 $\mathrm{E}$ 级。结果表明, 河流改造前后相比, 改造后属于 A 级和 B 级的植物 种增多了, 属于 $\mathrm{C}$ 级、 $\mathrm{D}$ 级和 $\mathrm{E}$ 级的植物种减少了。

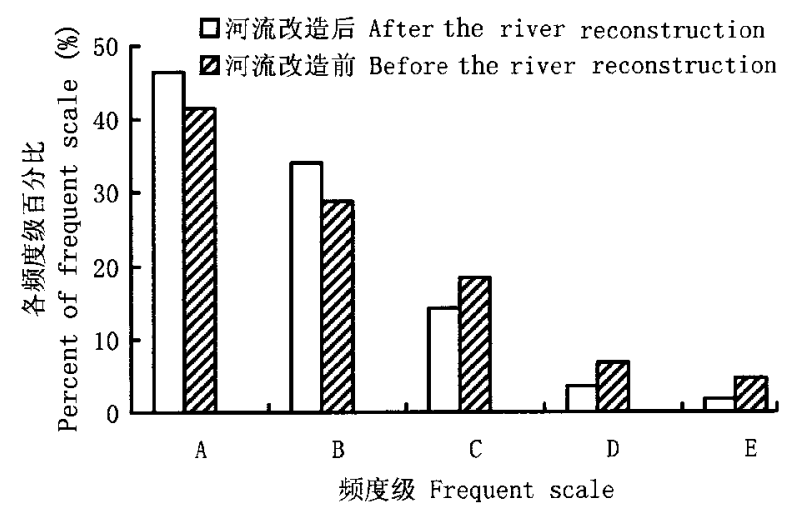

图 2 河流改造前和改造后的频度图解

Fig.2 Frequency diagram of plant before and after the river reconstruction

\section{3 河流改造前后的物种成份相似性分析}

对样方调查的结果表明, 河流改造前和改造后 共有 51 个相同物种，用 Sørensen 指数公式计算河流 改造前后的物种组成成份相似性，Sørensen 指数值 为 0.708 。单从 Sørensen 指数值看, 河流改造前后的 物种组成成份的相似性仍然比较高, 但如果没有河 流改造工程的影响,两者之间的 Sørensen 指数值接 近于 1 ,意味着河流改造使 Sørensen 指数值明显减小 
表 1 各样方的野生维管植物物种数和多样性指数

Table 1 Species number and diversity of native vascular plant in different sampling plot

\begin{tabular}{|c|c|c|c|c|c|}
\hline \multirow{2}{*}{$\begin{array}{l}\text { 样方号 } \\
\text { Sampling } \\
\text { plot No. }\end{array}$} & \multicolumn{2}{|c|}{ 样本 A Sample A } & \multirow{2}{*}{$\begin{array}{l}\text { 样方号 } \\
\text { Sampling } \\
\text { plot No. }\end{array}$} & \multicolumn{2}{|c|}{ 样本 B Sample B } \\
\hline & $\begin{array}{c}\text { 物种数 } \\
\text { Species number }\end{array}$ & $\begin{array}{l}\text { Shannon-Weiner 指数 } \\
\text { Shannon-Weiner index }\end{array}$ & & $\begin{array}{c}\text { 物种数 } \\
\text { Species number }\end{array}$ & $\begin{array}{l}\text { Shannon-Weiner 指数 } \\
\text { Shannon-Weiner index }\end{array}$ \\
\hline$A_{1}$ & 32 & 3.192 & $\mathrm{~B}_{1}$ & 14 & 1.754 \\
\hline $\mathrm{A}_{2}$ & 37 & 3.316 & $\mathrm{~B}_{2}$ & 16 & 2.198 \\
\hline $\mathrm{A}_{3}$ & 26 & 2.614 & $\mathrm{~B}_{3}$ & 18 & 2.426 \\
\hline $\mathrm{A}_{4}$ & 16 & 1.912 & $\mathrm{~B}_{4}$ & 13 & 1.732 \\
\hline $\mathrm{A}_{5}$ & 29 & 2.735 & $\mathrm{~B}_{5}$ & 17 & 1.982 \\
\hline $\mathrm{A}_{6}$ & 20 & 2.354 & $\mathrm{~B}_{6}$ & 10 & 1.031 \\
\hline $\mathrm{A}_{7}$ & 39 & 3.417 & $\mathrm{~B}_{7}$ & 11 & 1.214 \\
\hline $\mathrm{A}_{8}$ & 30 & 2.016 & $\mathrm{~B}_{8}$ & 16 & 1.925 \\
\hline $\mathrm{A}_{9}$ & 33 & 2.792 & $\mathrm{~B}_{9}$ & 18 & 1.826 \\
\hline$A_{10}$ & 24 & 2.272 & $\mathrm{~B}_{10}$ & 15 & 1.021 \\
\hline$A_{11}$ & 16 & 2.172 & $\mathrm{~B}_{11}$ & 18 & 1.969 \\
\hline $\mathrm{A}_{12}$ & 31 & 2.638 & $\mathrm{~B}_{12}$ & 21 & 2.102 \\
\hline$A_{13}$ & 17 & 1.961 & $\mathrm{~B}_{13}$ & 19 & 1.984 \\
\hline $\mathrm{A}_{14}$ & 35 & 3.324 & $\mathrm{~B}_{14}$ & 18 & 1.975 \\
\hline $\mathrm{A}_{15}$ & 38 & 3.410 & $\mathrm{~B}_{15}$ & 17 & 1.726 \\
\hline$A_{16}$ & 37 & 3.215 & $\mathrm{~B}_{16}$ & 21 & 1.957 \\
\hline$A_{17}$ & 27 & 2.638 & $\mathrm{~B}_{17}$ & 25 & 2.043 \\
\hline$A_{18}$ & 28 & 2.592 & $\mathrm{~B}_{18}$ & 16 & 1.291 \\
\hline $\mathrm{A}_{19}$ & 25 & 2.172 & $\mathrm{~B}_{19}$ & 19 & 1.995 \\
\hline $\mathrm{A}_{20}$ & 24 & 2.328 & $\mathrm{~B}_{20}$ & 21 & 2.093 \\
\hline $\mathrm{A}_{21}$ & 22 & 2.174 & $\mathrm{~B}_{21}$ & 20 & 1.962 \\
\hline $\mathrm{A}_{22}$ & 21 & 2.013 & $\mathrm{~B}_{22}$ & 23 & 1.916 \\
\hline $\mathrm{A}_{23}$ & 25 & 2.361 & $\mathrm{~B}_{23}$ & 22 & 1.984 \\
\hline $\mathrm{A}_{24}$ & 30 & 2.361 & $\mathrm{~B}_{24}$ & 17 & 1.732 \\
\hline $\mathrm{A}_{25}$ & 26 & 2.261 & $\mathrm{~B}_{25}$ & 19 & 1.926 \\
\hline $\mathrm{A}_{26}$ & 29 & 2.410 & $\mathrm{~B}_{26}$ & 18 & 2.012 \\
\hline $\mathrm{A}_{27}$ & 21 & 2.281 & $\mathrm{~B}_{27}$ & 17 & 1.826 \\
\hline $\mathrm{A}_{28}$ & 25 & 2.017 & $\mathrm{~B}_{28}$ & 18 & 1.984 \\
\hline $\mathrm{A}_{29}$ & 26 & 2.163 & $\mathrm{~B}_{29}$ & 17 & 1.872 \\
\hline $\mathrm{A}_{30}$ & 23 & 2.098 & $\mathrm{~B}_{30}$ & 19 & 1.893 \\
\hline
\end{tabular}

表 2 两样本之间的单因素方差分析

Table 2 One-factor analysis of variance between two samples

\begin{tabular}{|c|c|c|c|c|}
\hline & \multicolumn{2}{|c|}{$\begin{array}{c}\text { 物种数 } \\
\text { Species number }\end{array}$} & \multicolumn{2}{|c|}{$\begin{array}{l}\text { Shannon-Weiner 指数 } \\
\text { Shannon-Weiner index }\end{array}$} \\
\hline & $F$ & $F_{158,0.01}$ & $F$ & $F_{158,0.01}$ \\
\hline $\begin{array}{l}\text { 样本 } \mathrm{A} \text { 与样本 } \mathrm{B} \text { 之间 } \\
\text { Between sample } \mathrm{A} \text { and sample B }\end{array}$ & 51.076 & 7.12 & 40.876 & 7.12 \\
\hline
\end{tabular}

\section{4 讨 论}

从对汾河太原段改造前后两次随机抽取的样方 中的野生维管植物调查结果可以看出 :一方面, 在 河流改造后重新抽取的 30 个样方中比在河流改造
前所抽取的 30 个样方中减少了小灯芯草 (Juncus bufonius)、角蒿 (Incarvillea sinensis)、旋覆花 (Lnula japonica)、小蓬草 (Conyza canadensis)、狭叶紫苑( Aster lavandulaefolia)、无芒稗 (Echinochloa crusgalli)、长蓦 鸡眼草 ( Kummerowia stipulacea) 、苦马豆 (Swainsonia 
salsula )、菊叶香藜 (Chenopodium foetidum)、刺穗藜 (Chenopodium aristatum)、软毛虫实 (Corispermum puberulum)、盐地碱蓬 ( Suaeda salsa)、北美苋 (Amaranthus blitoides)、龙葵( Solanum nigrum)、曼陀罗 (Datura stramonium)、菖蒲 (Acorus calamus)、灰背老鹳草 (Geranium wlassowianum)、臭椿 (Ailanthus altissima)、 圆叶牵牛 (Pharbitis purpurea)、获藜 (Tribulus terrestris)、苟麻 (Abutilon theophrasti)、益母草( Leonurus japonicus)、细叶益母草 (L. sibiricus)、扁秆口草 (Scirpus planiculmis)、异型莎草 (Cyperus difformis)、水蜈蚣 (Killinga breviflia)、多花苔草 (Carex karol)、紫穗槐 (Amorpha fruticosa)、黄花草苜樨（Melilotus officinalis)、狼尾草 ( Pennisetum alopecuroides)、大画眉草 (Eragrotis cilianensis)、苍耳 (Xanthinum sibiricum)、野 艾蓠 (Artemisia lavandulaefolia)、菊叶委陵菜 (Potentilla tanacetifolia)、鳢肠 (Eclipta prostrata) 和鬼针草 (Bidens bipinnata) 共 37 种野生维管植物; 另一方面, 在河流改造后重新抽取的 30 个样方中, 又新迁入了 在河流改造前所没有的地锦草 (Euphorbia humifusa)、早开堇菜( Viola prionantha)、球穗莎草(Cyperus glomeratus)、细叶茨藻 ( Najas graminea) 和浮叶眼子菜 (Potamogeton natans) 共 5 种野生维管植物, 单从野 生维管植物物种数看, 增减相抵, 实际上改造后比改 造前减少了 32 个野生维管植物种, 减少幅度明显。 方差分析结果是, 汾河改造前后的野生维管植物物 种数和物种多样性指数的差异极显著, 从统计学规 律上进一步证明了河流改造工程造成了河流生态系 统中的野生维管植物物种数明显减少, 并使野生维 管植物物种多样性明显降低的规律。汾河改造工程 之所以能够使该河段野生维管植物物种数出现明显 减少和使该河段野生维管植物物种多样性出现明显 降低的现象，其原因是在汾河改造过程中，一方面摧 毁了部分原有的天然植物群落, 另一方面也使原先 只在暴雨之后短时间内过水的沙土质河床、沙洲以 及天然形成的缓坡沙土质岸滩消失了, 取而代之的 是人工硬化的石质河床、钢筋混凝土河堤和人工平 整后的土质比较一致的河岸和常年蓄水的河湖环 境, 这样就使改造后的河流生态系统失去了在自然 演化过程中所形成的原有生境的多样性，从而导致 原来在沙土质河床上和缓坡沙土质堤岸处生长的部 分湿生植物和中生植物从河流生态系统中消失了。

从频度图可以看出, 河流改造前后相比, 频度 较低的 $\mathrm{A}$ 级和 $\mathrm{B}$ 级的野生维管植物种占总物种数 的百分比分别增加了 $5.0 \%$ 和 $5.2 \%$, 而频度较高的
$\mathrm{C}$ 级、 $\mathrm{D}$ 级和 $\mathrm{E}$ 级的植物种则分别下降了 $4.1 \%$ 、 $3.3 \%$ 和 $2.8 \%$ 。这表明城市河流改造工程明显降 低了河流生态系统中部分物种分布的均匀性, 使河 流生态系统中的更多野生维管植物种呈现不均匀分 布。

从汾河太原段改造前后植物群落之间的 Sørensen 指数值的明显减小可以看出, 汾河改造工 程对河流生态系统中的野生维管植物物种组成成份 也有一定影响, 不但使河流生态系统中原有的植物 种类大量减少, 而且还由于环境的改变使河流生态 系统中新迁入了一些河流改造前所没有的物种。在 河流改造后，一方面由于市区排放的污水沿两侧暗 渠排往下游, 使改造后新建的洪水渠和” 河湖” 的水 质得到改善, 于是耐污染能力较弱的浮叶眼子菜和 细叶茨藻等水生植物便出现在改造过的河段中, 另 一方面由于土方的挖掘和填埋, 在河流两岸形成了 一些裸露地面，尽管在这些裸露地面上种植了人工 草坪和零星的乔木、灌木植物, 但由于植物物种数 少, 物种之间的竞争比较弱, 于是繁殖力强但竞争力 弱的地锦草、早开堇菜和球穗莎草等陆生植物便率 先侵入并定居在改造过的河段上。这表明城市河流 改造工程对城市河流生态系统中的野生维管植物物 种组成成份也有一定影响。

在进行了汾河太原段河流改造工程对城市河流 生态系统中的野生维管植物影响研究的基础上, 提 出了今后在进行城市河流改造时, 应采用空心水泥 砖以斜坡式构筑堤岸, 河床不应进行人工硬化, 而应 保持原有的自然状态，尽量保留原有的沙洲和自然 形成的岸滩, 为野生植物保留适宜的生存场所, 以减 轻河流改造工程对野生维管植物造成的不良影响。

\section{参 考 文 献}

Cui WZ (崔伟中) (2003). Engineering measures of river ecology in Japan and its draw lessons. Pearl River (人民珠江)，(5), $1-4$. (in Chinese)

Dong ZR (董哲仁) (2004) . The evolution and tendency of development of the ecological engineering in harness river. Water Resources and Hydropower Engineering (水利水电技术), 35, 39 - 41. (in Chinese)

Du SR (杜淑如), Shi DH (石东海), Hao FQ (郝福全), Cai DW(蔡殿威), Zuo HF(左海风), Yan YC(阎玉才) (1997). Investigation of draining waste in Taiyuan section of Fenhe River. Shanxi Hydrotechnics (山西水利科技)，115，56-60.（in Chinese with English abstract)

Du RQ (杜荣骞) (1985). Biostatistics (生物统计学). Higher Education Press, Beijing, 2-5. (in Chinese) 
Freeman RE, Ray RO (2001). Landscape ecology practice by small scale river conservation groups. Landscape and Urban Planning, $56,171-184$

Fabos JG (2004) . Greenway planning in the United States: its origins and case studies. Landscape and Urban Planning, 68, $321-342$.

Han J (韩静), Zheng F (郑凡) (2003). Water pollution in Taiyuan and its prevention. Shanxi Hydrotechnics (山西水利科 技), 149, 39-40. (in Chinese with English abstract)

Konishi H (2000). Formation of hub cities: transportation cost advantage and population agglomeration. Journal of Urban Economics, $48,1-28$.

Li B (李博) (1993). General Ecology (普通生态学). Inner Mongolia University Press, Huhhot, 104-107. (in Chinese)

Ma GQ (马国庆) (2003). Management Statistics (管理统计). Science Press, Beijing, 210-216. (in Chinese)

Song QH (宋庆辉), Yang ZF (杨志峰) (2002). Thinking of integrated management of urban river in China. Advances in Water Science (水科学进展), 13,377-382. (in Chinese with Eng- lish abstract)

Wu BS (吴保生), Chen HG (陈红刚), Ma JM (马吉明) (2004). Impact of channelization on the ecological environment in Kissimmee River, USA. Water Resources and Hydropower Engineering (水利水电技术) , 35(9), 13-16. (in Chinese with English abstract)

Wu ZH (吴中华), Yu D (于丹), Tu MH (涂芒辉), Xu XW (徐新伟) (2002). Studies on the diversity of aquatic plants in Hanjiang river. Acta Hydrobiologica Sinica (水生生物学报), 26, 348 - 356. (in Chinese with English abstract)

Yan SY (阎水玉), Wang XR (王祥荣) (1999). Study on the roles and applied ways of urban river in urban ecological construction. Urban Environment \& Urban Ecology (城市环境与城 市生态), 12, 36-38. (in Chinese with English abstract)

Zhang M (张明), Cao MY (曹梅英) (2002). An elementary introduction to renovation of city river and protection of ecological environment. Chinese Water and Soil Conservation (中国水土保 持), 9, 33-34. (in Chinese with English abstract)

责任编委 : 傅伯杰 责任编辑 : 张丽赫 